\title{
On Cultivation Strategies of Youth Values
}

\author{
Zhang Fan, Li Sen \\ Southwest University, Chongqing, China
}

\begin{abstract}
The youth is a critical stage of life for personal and professional development, which is also an important period for cultivation of values. Given the characteristics of young people, we need to use systematic cultivation strategies to cultivate their values. Especially, we are expected to use different approaches of family education, school education, and social education, combining with methods of persuading and guiding, role-model motivation, practice cultivation, and teaching penetration to cultivate youth values comprehensively.
\end{abstract}

Keywords: youth values, cultivation, strategies

\section{Introduction}

Generally speaking, values are people's basic views and general understanding of value. To human life, the meaning of values lies in its position and leading role of life value. People's values affect the quality of their survival and development, and even affect the future development of social groups. Known as the golden stage of individual development, the youth stage is an important stage of life. Meanwhile, the youth stage is a key stage of shaping, forming, and stabilizing individual values, too. Thus, the youth values will be influenced by individual's physical and psychological factors, education orientation, social environment, and other factors. In addition, more attention should be paid to all kinds of influential factors so as to cultivate youth values and construct systematic cultivation strategies.

\section{Features of Young People}

In order to achieve the desired educational results, we might have deep understanding of the education object. The cultivation of youth values is a broad educational process. With a whole systematic cultivation strategies construction blueprint in mind, we need to understand the youth themselves and grasp the characteristics of the development of their values.

\section{The Suddenness of the Change in the Physical and Mental Development of the Youth}

"Youth" is a collective concept and does not point to a specific individual. When we use the concept of youth, it means a group of 20 -somethings with a common existence and sharing with common characteristics. Although there are different bases and standards on the affirmation of "youth" concept worldwide, it does not affect people to grasp the intrinsic unity of youth groups. Generally speaking, people between 15 and 25 years old are seen as adolescents. There are also some researchers see people between 15 and 30 years old as adolescents (Huang, 2009). The "youth" here mainly refer to people between 18 and 25 years old, a specific group being receiving higher education. The most surficial feature of the youth in such a period is the 
mutability of physical and mental development. They are at a particular stage of life and life development, and they are growing maturely in the physical function and psychological development level rapidly, exhibiting a variety of mutations. With their physical and mental changes, their individual demands grow suddenly and rapidly, such as their specific performance for knowledge, employment, love, and entertainment. In short, the formation and development of youth values based on the actual changes in their physical and mental affects, guiding the subsequent growth and development of the young individuals, have a close relation with the youth's physical and mental development.

\section{The Independence of the Youth's Way of Thinking}

Compared with the juvenile period, the youth's way of thinking began to show more independence, autonomy, or even criticalness. At this time, they can not only realize every physiological part of their own and its functions, but also aware of their own perception, emotion, will, and purpose of psychological factors and its functions. This series of changes reflected in the way of thinking is their growing self-awareness and the developed ability to think independently. They began to believe their own ability and to show "self-confidence". For external education and persuasion, they began to no longer believe and accept as juvenile. Sometimes, they even offer different and opposite views to educators, showing rebellion and criticalness. They began to think about all the things with doubt and critical eyes. They do not satisfy with the human experience and theories from books, but like to question, dare to argue, have the courage to imagine, and will actively express personal views. However, in order to be more conductive to the youth's growth, a critical spirit should be educated and guided by scientific external education. The cultivation of youth values needs to accurately grasp the features of the way of thinking in the youth.

\section{The Variability of Youth Values}

The common characteristics of youth groups, such as the changes in physical and mental or way of thinking aspects, will eventually be reflected in youth values. The variability of youth values arises with the rapid development of independence and self-consciousness in the youth. With the strengthening of self-consciousness in the youth, they began to seek for novelty and dare to exploit something new or embrace fashion. On the option of values, they no longer passively accept traditional or mainstream values inputted by adults. They are inclined to seek for all sorts of new value standard, value orientation, and value goal with the development of the times and trying to establish their own values which can reflect the characteristics of the youth. Meanwhile, such a kind of youth values is not stable, but pluralistic and open. People can see the youth not only follow the positive and healthy mainstream values, but also conform to non-mainstream and sub-healthy values in the real life. Of course, the final development trend of youth values is affected by many factors and the core factor is external education. The characteristics of the youth themselves determine the strong plasticity characteristic in youth values.

\section{Educational Guidance to Cultivate Youth Values}

Relying on education and educational guidance is the basic way to cultivate youth values. Firstly, family education should participate in cultivating youth values actively, founding good basis for youth values formation. Secondly, school education should play the main role to help young people establish scientific and reasonable value goal, standard, and orientation. Finally, social education should create favorable conditions for the cultivation of youth values by optimizing the external environment. 


\section{Paying Attention to School Education in the Cultivation of Youth Values}

School is an important place for the youth's socialization, which has a comprehensive, systematic, and profound impact on youth values and also has a dominant role in the formation of youth values. Especially in colleges and universities, they have the environmental factors with values, which is a special place for planned, purposeful, and organized youth values education The effects of school education on youth values mainly manifested in three aspects: (a) inner educational thoughts and concepts of school education; (b) campus culture construction; and (c) educators' words and deeds demonstration. Therefore, school education plays a leading role in youth values education. Schools should provide the correct orientation for the youth from ways of school system, school running idea, school spirits, and so on. At the same time, we should also pay attention to the construction of campus culture in order to realize the function of campus culture in value internalization, value innovation, and value edification, letting the youth identifying and accepting the common values unconsciously. In addition, we should give particular attention to the influence from educators in youth values, because imparting knowledge means the transmission of values and the thought-leading is the shaping of youth values.

\section{Consolidating the Basic Function of Family Education in the Cultivation of Youth Values}

Family has self-evident influences on its individuals and family environment is an important factor affecting the cultivation of youth values. As the saying goes, "Parents are the best teachers of their children". Indeed, parental influence is the most important way of youth values cultivation (Guan, 2012). From the ways of education level, parents often realize the effect on youth values by all kinds of family education, and this kind of impact tends to be more fundamental, even affecting the value preference and value choice of young people lifetime. In the long process of contacting with family members, the youth will always be influenced subliminally by the values implanted by family members intentionally or unintentionally. Therefore, the cultivation of youth values must seek the foundational support of family education. Family should assume corresponding responsibility for cultivating youth values. Parents should run through the cultivation of youth values to all aspects of their daily lives, transforming the scientific and ideal value orientation, value recognition, and value standard into youth values with an effective carrier and form, then continue to consolidate them .

\section{Strengthening Social Education to Support the Cultivation of Youth Values}

Any form of values is a subjective reflection of the objective social existences in people's mind. The social environment determines people's basic value concept. Young people have just involved in social environment and begin to construct social relationships. The shaping of youth values is bound to educated by the social environment. The socio-economic environment, cultural environment, and other factors can also influence the formation and development of youth values at different extent. On one hand, economic development decides the basic attributes of the whole social values. On the other hand, cultural construction affects the atmosphere of the values formation and development. And the youth's value choice is directly determined by moral construction. Thus, cultivating youth values needs to strengthen the supporting role of social education to family and school education, and to enhance the combined fore between them. Therefore, cultivating youth values should continuously optimize the social environment, especially strengthen the ideological and moral construction, so as to strengthen the cultivation significance of social environment for youth values. 


\section{Some Effective Educational Methods of Cultivating Youth Values}

Cultivating youth values not only relies on some specific educational approaches, but also cannot do without the support of technical methods. Applying diversity and effective educational methods can achieve the desired effect of youth values education.

\section{The Method of Persuading and Guiding}

The method of persuading and guiding is the general method and typical practice of youth values education. In order to make the youth establish scientific and reasonable values, their value recognition could be shaped under the educator's explanation of value facts and reasons (Shi, 2007). The advantage of the method of persuading and guiding lies in the explanation of value knowledge, concept, and theory to the youth. Then the youth can achieve value consensus and form right value standpoints and opinions by participating in educational activities under the guidance and help of educators. Applying the method of persuading and guiding into youth values cultivation should pay attention to scientificalness, democracy, and emotionality. The realistic value knowledge and theory itself teaching to the youth should be scientific and reasonable, which can be accepted by them persuasively. In the process of persuading and guiding, we should pay attention to respecting the subjectivity of the youth and establish an equal and harmonious educational relationship, letting the youth be able to participate actively in the value discussion and debate so as to get the truth of values. Educators also need to put the emotional factors into persuading and guiding activities, making the youth enhance value identity in the emotional resonance and ideological consensus.

\section{The Method of Example Motivation}

The method of example motivation is a particular method of youth values cultivation. It focus on collecting the typical case of youth values cultivation, which has the characteristics of infectivity and figurativeness (Zheng, 2010). In simple terms, it is to use models who have scientific value concept, reasonable value evaluation, and excellent practical capacity to motivate the youth to form the targeted youth values. John Locke, the famous British educator once said, "Nothing sink so gently and so deeply into men's minds as examples" (Locke, 2007). This is the best interpretation of the advantage of methods of example motivation in values education. Using the method of example motivation in youth values education requires selecting good examples suitable for youth physical and mental features. These examples must be able to be identified by the youth and can produce attractive and excitation force to them. Meanwhile, educators must learn to leading the youth's consciousness and initiative in following the examples, letting them grasp example's spiritual essence and value orientation during their amazement, love, admiration, and worship to examples in order to guide their behavior and form good values.

\section{The Method of Practice Cultivation}

The method of practice cultivation refers to an youth values educational method which goes through organizing and guiding the youth to participate in or carry out a variety of social practices purposely. Educators will carry out youth values education and realize the expected educational target in practice activities. The method of practice cultivation has multiple advantages of testing, improving, and strengthening in youth values cultivation. Whether youth values are compatible with the society or not, this can be tested in social practice. If they are not compatible, practice activities can help the youth improve their values and constantly transform the required external values into the youth's inner value concept. Applying the method of practice cultivation 
cannot work without scientific guidance, and the practice activities must be objective and pertinent. With different educational objects, we need to plan and arrange the contents and forms of practice activities carefully and reasonably, making the youth contact and feel the social value contents, and gradually internalize the value cognition, value orientation, and value criterion in practice activities into their own values.

\section{The Method of Teaching Penetration}

The method of teaching penetration refers to educational and guidance methods of youth values, which is based on the different professional education accepted by the youth, penetrating youth values education into different professional courses and providing them values education and guidance when they are accepting the training of professional technology. The method of teaching penetration has characteristics and advantages of hiddenness, permeability, and persistence in the cultivation of youth values. Applying this method requests educators to have a strong sense of responsibility, cooperation, and self-discipline consciousness. The cultivation of youth values is a systematic project. Every educator related to the youth has the responsibility of educating and guiding them, not only the duties of some particular educators. Therefore, educators should have a strong sense of responsibility of education. Similarly, because the formation of youth values is a systematic process affected by the impact of various aspects, educators must have a sense of collaboration and teamwork spirit and committed to the development of youth values. In addition, the words and deeds of the educators themselves is the most vivid education mode, which requires educators to make models for the youth and strengthen self-discipline of introspection, and guide the healthy development of the youth.

\section{Conclusion}

Adolescence is a key period for individual life development both personally and professionally. Young people have some features of being full of energy, active thinking, and broadminded, which make them have unique characteristics of independence, expansibility, and deformability in their values. Therefore, cultivating youth values should systematically apply ways of school education, family education, and social education, combing with many effective educational methods gradually on the basis of grasping the features of youth group and understanding the uniqueness of their values accurately.

\section{References}

Guan, Y. L. (2012). Children should be educated like this. Yanglin: Northwest A\&F University Press. Hansson, S. O. (2011). The structure of values and norms. Cambridge, U.K.: Cambridge University Press. Huang, R. S. (2009). On the science of youth. Chengdu: Sichuan People's Press.

Koertge, N. (2005). Scientific values and civic virtues. Oxford, U.K.: Oxford University Press. Locke, J. (2007). Some thoughts concerning education. Beijing: People's Education Press.

Riley, S. S. (2009). How to generate values in young children. Raleigh, N.C.: Boson Books Press. Shi, H. B. (2007). On the education of youth values. Hefei: Anhui People's Press.

Zheng, J. X. (2010). Development of youth values. Zhengzhou: Yellow River Conservancy Press. 